\title{
GESTÃO DOS RECUH NATURAIS NA REGIÃO DO TOCANTINS ATRAVÉS DE AC




\section{GESTÃO DOS RECURSOS NATURAIS NA REGIÃO DO BAIXO TOCANTINS ATRAVÉS DE ACORDOS DE PESCA}

\section{A QU I L E S S I M Õ E S}

UNIVERSIDADE FEDERAL do PARÁ, BELÉM, BRASIL

$$
\text { SARA CORREA DIAS }
$$

UNIVERSIDADE FEDERAL DO PARÁ, CAMETÁ, BRASIL

$$
\text { ORIANA ALMEIDA }
$$

UNiVersidade Federal do PARÁ, BelÉm, Brasil

$$
\text { SÉRGIO RIVERO }
$$




\title{
GESTÃO DOS RECURSOS NATURAIS NA REGIÃO DO BAIXO TOCANTINS ATRAVÉS DE ACORDOS DE PESCA
}

Resumo

O artigo trata da construção da ação pública como produto das múltiplas formas de interação entre a ação coletiva e a ação governamental, nas quais se inscrevem processos tradutores dos modos de organização dos camponeses para o uso e apropriação dos recursos naturais em nível do território. Optou-se pela pesquisa qualitativa, apoiada na observação participante e na realização de entrevistas semiestruturadas. A análise dos processos organizacionais, como a constituição de associações na busca de alternativas econômicas e de segurança alimentar, dos acordos de pesca para a gestão sustentável dos recursos pesqueiros, mostra como os camponeses recompõem seus modos de reprodução por meio da ação pública, apresentando as formas de resistência desses camponeses frente a impactos socioambientais e processos de expropriação. Os dados nos permitiram identificar que um dos principais impactos nas últimas décadas na gestão dos recursos naturais foi a construção da hidrelétrica de Tucuruí; além disso, os acordos de pesca tornaram-se uma maneira de lidar com a intensificação da pesca devido ao consequente impacto da usina hidrelétrica. O sucesso dos acordos estudados aqui foi resultado de um processo genuíno iniciado nas comunidades. Outras experiências semelhantes, organizadas pela instituição governamental (estilo de cima para baixo) não resultaram em experiências bem sucedidas.

Palavras-chave: ação coletiva, recursos naturais, acordos de pesca.

\section{NATURAL RESOURCE MANAGEMENT IN THE LOWER TOCANTINS RIVER REGION THROUGH FISHING AGREE- MENTS}

\begin{abstract}
The article deals with the construction of public action as the product of multiple forms of interaction between collective action and government action, in which processes represents organization systems of farmers for the use and appropriation of natural resources. We used qualitative methods, participant observation and semi-structured interviews. The analysis of organizational processes as the creation of associations to improve governance system in general and fisheries agreements for the sustainable management of fishery resources, in particular, shows how the peasants structure their modes of reproduction through public action, to reduce environmental impacts and expropriation processes. As the main impact in the last decades has been Tucuruí hydroelectric power plant construction fish agreement has become a way to cope with intensification of fishing and consequent impact of the hydroelectric plant. The successes of the two agreements studied here
\end{abstract}


was a result of the genuine process initiated in the communities. Other experiences of similar agreements organized by governmental institution has not resulted in successful experiences.

Keywords: collective action, natural resources, fishing agreement.

\section{GESTIÓN DE LOS RECUROS NATURALES EN LA REGIÓN DEL BAJO TOCANTINS A TRAVÉS DE ACUERDOS DE PESCA}

\section{Resumen}

El artículo trata de la construcción de la acción pública como producto de las múltiples formas de interacción entre la acción colectiva y la acción gubernamental, en las cuales se inscriben procesos traductores de los modos de organización de los campesinos para el uso apropiado de los recursos naturales en nivel del territorio. Se optó por la investigación cualitativa, apoyada en la observación participante y en la realización de entrevistas semiestructuradas. $\mathrm{El}$ análisis de los procesos organizacionales, como la constitución de asociaciones en la búsqueda de alternativas económicas y de seguridad alimentaria, de los acuerdos de la pesca para la gestión sustentable de los recursos pesqueros, muestra cómo los campesinos recomponen sus modos de producción por medio de la acción pública, presentado las formas de resistencia de esos campesinos frente a impactos socioambientales y procesos de expropiación. Los datos nos permitirán identificar que uno de los principales impactos en las últimas décadas en la gestión de los recursos naturales fue la construcción de la hidroeléctrica de Tucuruí; además, los acuerdos de pesca se tornaron una manera de lidiar con la intensificación de la pesca debido al consecuente impacto de la central hidroeléctrica. El éxito de los acuerdos estudiados aquí fue resultado de un proceso genuino iniciado en las comunidades. Otras experiencias semejantes, organizadas por la institución gubernamental (estilo de arriba hacia abajo) no resultaron en experiencias muy exitosas.

Palabras-clave: acción colectiva, recursos naturales, acuerdos de pesca

Endereço do primeiro autor para correspondência: Núcleo de Ciências Agrárias e Desenvolvimento Rural/PPGAA/GEDAF - UFPA. Universidade Federal do Pará - Rua Augusto Corrêa, 01 - Guamá. CEP 66075110. Belém - PA. E-mail: moinaiu@gmail.com 


\section{INTRODUÇÃO}

A ação coletiva pode ser entendida como "toda ocasião na qual um conjunto de pessoas confia e aplica recursos, incluindo seus próprios esforços, para fins comuns" (Tilly et al. 1981, citado por Gohn 1997:66). Ela pode ser entendida também como uma forma de ação em sociedade, lado a lado da ação histórica (Touraine 2006) ou da ação subjetivada (Dubet 1987. Dubet \& Wieworka 1995). Ela é uma ação voluntária que assume necessidades tradicionalmente dadas por interesses privados, contribuindo para a criação, no seio das sociedades complexas, de espaços públicos, condicionando a instauração de novos modos e métodos de governança dos recursos e dos territórios (Melucci 2001). Assim, a ação coletiva é objeto de um intenso trabalho de re-conceptualização da ação em sociedade e das modalidades de construção de bens comuns.

Essa visão pretende integrar então a atividade humana não somente em sua dimensão de produção e gestão dos recursos (trabalho, produzir bens), mas também da vida pessoal e criativa dos camponeses (habitar em um lugar em particular, à beira do rio, por exemplo) e da participação na vida política e associativa (o que chamamos hoje a "participação" ou "aprendizagem participativa”).

É fundamental incluir nessa definição a relação com o Estado, mobilizando a noção de ação pública, ou seja, as interpenetrações estreitas, dinâmicas e complexas entre ação coletiva e ação governamental (Duran 1999, Lascoumes \& Le Galès 2007). A ação coletiva estaria, assim, intrinsecamente articulada à ação pública que é, por sua vez, uma nova maneira de conceituar a ação governamental, assumindo sua fragmentação, suas contradições locais, sua pluralidade, "substituindo o interesse geral mítico pelo interesse coletivo possível"
(Duran 1999).

A gestão dos recursos naturais - em geral - e da pesca - em particular - na Amazônia tem se dado de uma forma ampla, por meio do manejo comunitário ou de novos sistemas de co-manejo, em que os usuários organizam a gestão dos recursos naturais com algum nível de colaboração com o poder público.

Iniciativas comunitárias para regular a exploração dos lagos de pesca na várzea, por meio do manejo comunitário, têm uma história antiga (De Castro 1999). A natureza dessas iniciativas tem evoluído rapidamente, desde 1960, quando a expansão da pesca comercial levou ao aumento dos conflitos entre pescadores comerciais itinerantes e pescadores locais residentes na região de várzea (McGrath et al. 1993, De Castro 1999, Oliveira \& Cunha 2000, Pereira 2000, Smith 2000).

A literatura que aborda a ação coletiva mostra a importância dos sistemas participativos na gestão coletiva de bens comuns, pois vem definindo as modalidades de governança dos recursos e dos territórios (Gohn 1997, Lascoumes 2007, Leloup et al. 2005, Olson 1965, Simões 2007, Dubet \& Wieworka 1995). Na Amazônia, o sistema de co-manejo evoluiu a partir de iniciativas de manejo comunitário que não possuíam o apoio do governo e que estavam constantemente em conflito com os pescadores comerciais. Essa iniciativa ocorreu na Amazônia brasileira, assim como em alguns países próximos (Fernandez-Baca 1998, Smith 2000).

Os pescadores residentes na região de várzea da Amazônia, determinados a ter controle sobre os recursos pesqueiros dos seus lagos, passaram a definir regras para o uso dos recursos por meio de acordos de pesca. Esses acordos informais geraram conflitos tanto entre pescadores lo- 
cais, como entre pescadores comerciais. Tais conflitos aconteceram, basicamente, porque os pescadores comerciais não reconheciam a autoridade das comunidades para fechar seus lagos ou regular a pesca dentro deles. Com base na regulamentação federal de pesca ou no Código Federal das Águas, os pescadores comerciais argumentaram que eles possuíam livre acesso aos corpos de água que não estivessem integralmente dentro de propriedades privadas e, portanto, de acordo com as leis federais, tinham direito de pescar nos rios e lagos da várzea amazônica.

As comunidades locais fizeram pressão para que o governo legalizasse os Acordos de Pesca e, no final da década de 1990, o governo central garantiu os direitos de manejo de lagos aos pescadores locais; esta garantia foi regulamentada em 2002, por meio de instrução normativa (Instrução Normativa número 29). Essa lei permitiu que os pescadores de subsistência regulassem os lagos próximos as suas comunidades por meio de acordos de co-manejo (Vidal 2010). Com essa legislação, as comunidades passaram a ter o poder de definir as regulamentações de pesca.

Segundo a nova lei, para que o acordo seja válido, ele precisa seguir as legislações superiores e estabelecer regras por meio de um processo participativo e predefinido dentro da comunidade. Uma vez aprovado o acordo, prevê-se que a comunidade receba um treinamento do governo para monitorá-lo e ter poder de registrar e reportar qualquer caso de infração à agência ambiental federal. Com essa legislação, as comunidades ganharam muito poder.

Os acordos podem restringir o uso de determinados arreios de pesca, limitar o tamanho e a potência dos barcos, limitar a captura por espécie, definir os períodos de pesca e outras medidas relevantes para seus lagos (De Castro 1999). Com essa lei, as regulamentações centrais do manejo foram integradas às iniciativas de manejo comunitário e assim iniciou-se o sistema de co-manejo na Amazônia.

A história e a intensidade dos acordos de co-manejo na Amazônia variam de região para região ou mesmo de estado para estado. Os estudos dos sistemas de co-manejo na Amazônia têm enfocado a região do Baixo Amazonas, nos arredores de Santarém, onde mais de 100 comunidades de várzea estavam envolvidas em algum tipo de acordo. Dos acordos mapeados, metade envolvia apenas uma comunidade e 32\% envolviam duas comunidades (De Castro 1999). Esses acordos regulavam o uso do arreio de pesca, o período, as áreas de operação e o tipo de pesca (comercial versus subsistência).

Desde 1992, o número de acordos que regulam outras atividades além da pesca, como caça, o uso de pastos pelo gado e a exploração madeireira, cresceu aproximadamente 35\%. Em seu estudo detalhado de acordos, De Castro (1999) mostrou que as regulamentações mais frequentes nos acordos são as restrições sazonais (75\%), a proibição do uso de malhadeiras (59\%) e a proibição da pesca comercial $(56 \%)$. Apesar de os pescadores não poderem impedir o acesso de pessoas de fora, a proibição das malhadeiras torna a pesca comercial economicamente inviável.

Na região de Tefé, o manejo comunitário evoluiu a partir da criação da Reserva do Mamirauá, em 1990, e do Grupo de Desenvolvimento e Preservação (GDP), fundado em 1992. A reserva do Mamirauá ocupa uma área de $11.240 \mathrm{~km}^{2}$, localizada próximo à cidade de Tefé e as restrições sobre o uso dos recursos pesqueiros foram iniciadas desde 1996 como parte do plano de manejo da reserva. As restrições geraram diversos conflitos entre os residentes da reserva e os pescadores de fora. No 
início da implantação do sistema, Queiroz (1999) constatou que em menos de dois anos houve mais de 661 invasões por pescadores de fora da área focal da reserva (20\% da área da reserva).

O sistema de manejo comunitário na reserva é diferente, em virtude da legislação da reserva poder ser muito mais restritiva do que os acordos de pesca. O manejo comunitário na reserva pode proibir os pescadores de fora nas áreas de pesca, ao contrário das comunidades que possuem sistemas de co-manejo. Neste caso, as comunidades podem criar regulamentações de restrição, mas não podem excluir pescadores de fora.

Devido às restrições impostas aos pescadores comerciais nos lagos, houve um aumento no número de conflitos entre os pescadores das comunidades e os pescadores comerciais urbanos. A expansão do manejo comunitário nessa região causa um grande impacto para a frota de Tefé, uma vez que ela tem restrição de acesso a áreas em função da Reserva e do GDP.

Embora a expansão de acordos ao longo do rio Amazonas seja grande, isso não se aplica ao estuário. A ocorrência de habitats estuarinos, marinhos e fluviais na região fornece uma ampla variedade de opções de habitats à frota de Belém. Contudo, a maior parte da frota concentra seus esforços no estuário em espécies de água doce, como a dourada (Brachyplatystoma flavican) e a piramutaba (Brachyplatystoma vaillantii). Como poucos barcos saem do estuário para pesca no Baixo Amazonas e o manejo comunitário até agora não conseguiu estabelecer regras para os diversos ecossistemas da região de Belém (rios e baias), essa frota pode não ser muito afetada pelos acordos de co-manejo da várzea (Barthem et al. 1995).

O impacto da regulamentação do gover- no na pesca é pouco conhecido, mas já apresenta alguns estudos-chave. Almeida et al. (2009) fizeram um estudo comparativo entre lagos com manejo e lagos sem manejo, mostrando maior produtividade nos lagos manejados no Baixo Amazonas. De Castro et al. (submetido), em um levantamento sobre acordos da região de Cametá, revelam que os acordos nessa região tiveram menos sucesso que no Baixo Amazonas. Do grande número de acordos estabelecidos, poucos foram legalizados nessa região. O presente trabalho mostrará duas experiências de sucesso dos acordos de pesca na região do Estuário.

\section{METODOLOGIA}

O estudo foi realizado em duas comunidades rurais localizadas no município de Cametá, localizado no estado do Pará, nas quais a Associação Paraense de Apoio às Comunidades Carentes (APACC) vem atuando: Ilha Jaracuera Grande e Ilha Jacaré Xingu. Essa escolha se deu em função da história de sucesso com o acordo de pesca dessas duas comunidades.

As principais estratégias metodológicas no desenvolvimento da pesquisa envolveram o uso de metodologias de base qualitativa, como a observação participante e entrevistas semiestruturadas feitas com os pescadores nas comunidades escolhidas.

A observação participante ocorreu com a participação em encontros, seminários e outros eventos, nos quais as entidades de representação das comunidades participaram como promotoras ou convidadas. As informações das reuniões foram anotadas e gravadas. No que diz respeito às comunidades, foram feitas conversas informais com os camponeses dessas. Essas informações foram anotadas diariamente no caderno de campo. 
A aplicação de entrevistas semiestruturadas deu-se com pessoas-chave que participaram da construção das experiências, tanto como protagonistas das ações como na interlocução com os agentes estatais. Foram realizadas dez entrevistas, sendo cinco em cada comunidade escolhida. As entrevistas foram feitas a partir de um roteiro com questões-chave sobre o histórico dos acordos e sua organização para todos os entrevistados, mas organizado de forma a permitir o máximo de liberdade por parte dos entrevistados nas suas respostas, para possibilitar maior exploração dos assuntos referentes ao uso, manejo e gestão dos recursos naturais das comunidades rurais pesquisadas.

A pesquisa foi complementada com a análise de documentos produzidos pelas organizações camponesas, como atas de assembleias, relatórios de reuniões, projetos elaborados e acordos de pesca escritos.

\section{RESULTADOS \\ ACORDOS DE PESCA}

A Instrução Normativa 29 define um protocolo para elaboração de acordos de pesca. Como estrutura básica, um acordo só poderá ser aprovado se observar as legislações superiores e se for estabelecido por meio de um processo participativo dentro da comunidade a partir de protocolo estabelecido pela instrução normativa que envolve reuniões, participação dos envolvidos e apresentação das atas.

Todo o processo de redação do acordo deve ser enviado para a Gerência Executiva do Instituto Brasileiro do Meio Ambiente e Recursos Naturais Renováveis (IBAMA), para aprovação e redação final da Portaria. A minuta é encaminhada à sede do IBAMA em Brasília para a avaliação técnica e jurídica. Uma vez aprovada, o presidente do IBAMA assina a portaria e o acordo é publicado no Diário Oficial da União por meio de instrução normativa.

Dentro da estrutura de gestão, proposta por meio dos acordos de pesca, está previsto que pessoas da comunidade recebam um treinamento do governo para monitorar o acordo e essas pessoas treinadas poderão registrar e reportar qualquer caso de infração à agência ambiental federal. Após a aprovação por lei de acordos de pesca, o acordo teve vasta expansão na região do Baixo Amazonas e em seguida no estado do Amazonas (Pereira 2000). Na região do Tocantins, as iniciativas são muitas, mas poucas ainda legalizadas.

\section{A EXPERIÊNCIA DO ACORDO DE PESCA DE JARACUERA GRANDE}

A ideia de construir o acordo de pesca da comunidade de Jaracuera Grande surgiu entre 1999 e 2000, quando alguns pescadores sentiram a redução do pescado durante a captura. Os pescadores relatam que essa redução foi consequência da pesca intensiva que muitos pescadores praticavam na região. Na percepção dos envolvidos, a grande produção do rio Tocantins atraía muitos pescadores e aumentava o esforço de pesca.

Uma das soluções proposta pelos membros da comunidade foi regular a pesca por meio de um acordo. Em 2001, reuniram-se na localidade de Jaracuera Grande, os moradores locais em conjunto com a comunidade próxima e organizações civis e governamentais . Nessa Assembleia, foi aprovado e registrado em Ata o acordo de pesca de Jaracuera Grande, também foi estabelecida como área do acordo aquela "localizada na bacia hidrográfica do rio Tocantins, no município de Cametá, na microrregião de Cametá, no Estado do 
Pará, tendo como Ponto de Referência que está expresso na coordenada geográfica: PTR-S 204'28,3" e W 49²0'44,3” "'. Com isso, área do acordo abrange parte da ilha Jaracuera Grande, parte da ilha Jaracuerazinho e mais os corpos d'água que os cercam, constituído de um igarapé, seis furos e quatro enseadas.

$\mathrm{Na}$ assembleia, um grupo de pessoas foi nomeado para coordenar e fazer a mobilização dos pescadores para buscar um consenso entre os moradores em relação ao acordo. A princípio, não houve consenso, mas depois de vários meses, $90 \%$ dos membros aceitaram o acordo e só então foi feito o mapeamento de $750 \mathrm{~m}^{2}$ demarcando a área do acordo de pesca de Jaracuera Grande.

Em 2003, fundaram a Associação dos Produtores Familiares de Jaracuera Grande (ACORDAR), com 36 famílias. Por meio desta associação, essas famílias conseguiram recursos para a compra de malhadeiras e a da sede da Associação. Para isso, foi feito um projeto para o Banco do Brasil para a compra da rede do bloqueio (rede de cerco para capturar o mapará), canoas e materiais que precisavam para o manejo da pesca. A criação da associação foi fundamental para organização comunitária (Carvalho 1998).

No acordo de pesca, ficou definida a proibição de pesca de piaba, do uso de zagaia, tarrafa, flecha de fundo, puçá, malhadeira com malha de $25 \mathrm{~mm}$ ou menor, pari, malhadeira de poço e rede de lancear camarão. Também ficou proibida a caça com cachorro nas ilhas e a captura de animais silvestres (capivara, pato do mato, gambá etc.) nas quatro ilhas que fazem parte do processo de conservação do acordo.

Ainda que seja desnecessário dizer o que é permitido, no acordo ficou explicitada a permissão da utilização de rede aberta para o manejo do pescado, matapi grosso (um tipo de matapi feito com talas mais grossas) e pesca com caniço ou linha de mão. O manejo do peixe e do camarão passou a ser coordenado pela Comissão de Manejo e Pesca da Associação ACORDAR, desde que haja quantidade, qualidade e tamanho adequado do pescado e camarão e que esteja fora do período do defeso, da piracema e da reprodução do camarão.

O acordo também regulamenta a divisão da pesca, o que é uma inovação em relação às outras regiões da Amazônia. A captura é dividida $50 \%$ para os que realizam a pesca e $50 \%$ para a comunidade e para a associação ACORDAR. Do volume da associação, 40\% é vendido e o restante é dividido com todos que estão no local participando do evento. Se uma pessoa de outra comunidade quiser pescar no local, tem permissão, desde que entregue metade da captura para a associação ACORDAR. Essa parcela é utilizada para cobrir os custos da associação.

A elaboração do acordo foi marcada por inúmeras dificuldades e conflitos. O principal conflito diz respeito à concepção de que os recursos do rio eram de propriedade do morador localizado às suas margens. Houve cortes de redes e confrontos armados. Os fiscais da comunidade prendiam os materiais da pesca dos infratores do acordo e entregavam para o IBAMA. Porém, a maior crise enfrentada foi em 2006, quando os pescadores estavam em uma reunião da associação com os representantes do IBAMA e um grupo de pessoas (contra o acordo) invadiu a comunidade, resultando em um confronto físico em que pessoas foram gravemente feridas. Os indivíduos que defendiam o acordo se consideram vitoriosos no confronto e, a partir daí, consolidaram o acordo.

Como resultado dos conflitos, os pescadores se esforçaram, juntamente com o 
IBAMA, para regulamentar o acordo de pesca como instrumento jurídico conferindo legalidade ao mesmo. A celeridade desse processo foi fundamental para a sua sustentabilidade.

\section{FISCALIZAÇÃO DA COMUNIDADE}

Além das regras, os acordos precisam ser também monitorados, para que sejam efetivados ao longo do tempo. Uma das premissas do acordo de pesca é a observância das leis superiores, pois as equipes de fiscalização também averiguam as regras que eles consideram fundamentais para a sua manutenção, assim como a manutenção do defeso, período em que é proibido pescar várias espécies devido à desova. Em $1^{\circ}$ de novembro começa o período do defeso de várias espécies até 28 ou 29 de fevereiro, estabelecido pelo IBAMA, por meio de Portaria. Durante esses quatro meses, os pescadores recebem o seguro defeso correspondente à quantia de $\mathrm{R} \$ 2.488$, que visa compensar o que teria sido ganho com a pesca das principais espécies.

Para a pesca do mapará, uma das principais pescarias da região proibida durante o defeso, os pescadores de Jaracuera param as atividades em novembro e reiniciam em primeiro de março (Instrução Normativa 13 de 2011). Nesses quatro meses, os agentes ambientais se organizam para fazer a fiscalização. Foram escolhidos sete agentes ambientais, sendo cinco homens e duas mulheres. Esses agentes foram capacitados pelo IBAMA para o monitoramento e possuem a carteira de agente ambiental concedida pelo Instituto.

Cada agente tem sua equipe, formada por cinco pessoas, que fazem a fiscalização da área durante o dia e a noite e são remunerados pela ACORDAR. A associação possui uma mensalidade que recebe dos associados que é destinada às despesas da associação, como, por exemplo, manutenção e compra de materiais para pesca, pagamento de viagens para a sede municipal etc. $\mathrm{O}$ valor restante é dividido igualmente entre os fiscais. Esse pagamento é feito proporcional à participação de cada um nos grupos de fiscalização.

Os agentes ambientais voluntários desempenham um papel importante no acordo de pesca, pois além de fazer a fiscalização, são eles que trazem novas informações para a comunidade, obtidas em conferências, congressos e encontros. Além dessa função, formalmente eles apoiam o monitoramento (estudo e ou levantamento de dados) do acordo e do meio ambiente local. Eles também: orientam os comunitários locais e de outras comunidades sobre os acordos e legislação vigente; advertem as pessoas que descumprem o estatuto; e, denunciam aos órgãos competentes aqueles que prejudicarem o acordo de pesca e o meio ambiente, e outras determinações estabelecidas pela Instrução Normativa $n^{\circ}$ 19 de 05/11/2001 do IBAMA.

Nesse processo, os agentes ambientais acabam adquirindo novas competências, passam a obter um cabedal de conhecimentos sobre a legislação ambiental, dotam-se de informações e circulam por canais nos quais se discutem as possibilidades de projetos e oportunidades de apropriação dos benefícios vinculados a políticas públicas ambientais de desenvolvimento rural e de inclusão social, o que lhes confere legitimidade para atuar como agentes mediadores na interlocução entre as instituições estatais (IBAMA, Universidade, Secretarias de Meio Ambiente) e os camponeses pescadores. Essa é, sem dúvida, uma das dimensões da ação pública: a produção e reprodução de mediadores do desenvolvimento, em muitos casos podendo reproduzir relações tradicionais de dominação com base no clientelismo, praticando uma mediação 
alienante (D’Incao \& Roy 1995).

Atualmente, o acordo de pesca conta com o apoio da Polícia Militar, Colônia de pescadores Z-16 de Cametá, Sindicato dos Trabalhadores Rurais de Cametá e de Organizações Não-Governamentais. O IBAMA, que na época regulamentava os acordos de pesca, segundo os pescadores, não fornece o apoio necessário.

Segundo os entrevistados, a maior parte dos problemas enfrentados na região são consequências da construção da hidrelétrica de Tucuruí. O maior impacto foi causado sobre o estoque natural do pescado, que levou os ribeirinhos a adotarem práticas chamadas por eles predatórias (citam especialmente o puçá) para garantirem sua sobrevivência. "Antes da barragem, aqui tinha muito, muito mesmo curimatã, peixinho branco, aracu, pirapitinga, sardinha, branquinha, tinha com abundância e hoje não existem mais" (pescador entrevistado).

Além da redução de muitas espécies na região, o nível de água baixou nos rios e lagos da região, com o aparecimento de praias e pequenas ilhas, não permitindo a navegação no período de maré baixa e diminuindo as áreas úteis de pesca. Isso fez com que os pescadores se proliferassem para todas as áreas, inclusive as que deveriam ser preservadas, aumentando a pressão sobre o recurso pesqueiro para compensar a perda da diversidade do pescado, principal fonte protéica dos ribeirinhos. A qualidade da água foi substancialmente alterada, como nos revelou um morador do local:

“a água ficou todinha poluída, não dá nem para beber, a barragem foi muito ruim para nós; a gente sofre com doenças de todo tipo; dá muita hepatite, diarreia, coceira, vômito... perdemos nossa água. Muitas pessoas da ilha foram para a cidade para tentar uma vida melhor muitas vezes sem condição de se manter" (morador da ilha).

Apesar dos problemas, a comunidade é exemplo de uma organização que obteve sucesso, que tem como objetivo o trabalho solidário, baseado em acordos coletivos e em parcerias. O grupo também ajudou a criar outros acordos em outras comunidades como em Maracu Carmo, Juruaté, Pitiu e Praia Grande. Isso denota a capacidade de alcance da organização comunitária, mostrando que pode haver uma teia de aprendizagem social em torno da gestão dos recursos naturais que vem paulatinamente se construindo, cujos pontos centrais de construção são os acordos de pesca. A interação entre a ação coletiva e ação governamental, além de ser um processo de aprendizagem social, contribui para a constituição dos sujeitos do desenvolvimento para os quais a experiência é vivida como condição de historicidade (Simões 2007).

\section{A EXPERIÊNCIA DO ACORDO DE PES- CA DE JACARÉ XINGU}

O acordo de pesca da comunidade de Jacaré Xingu iniciou entre 1995 e 1998 (um dos acordos mais antigos do munícipio de Cametá), surgindo quando alguns pescadores começaram a perceber que várias espécies de peixes estavam se tornando escassas na região. Com o intuito de buscar melhorias para as famílias e diminuir os conflitos e disputas pelo pescado, os moradores iniciaram a elaboração de acordos de pesca na perspectiva de preservar e reduzir o esforço de pesca.

Para estruturar o acordo, foram reunidos membros da comunidade e do IBAMA, Polícia Militar, Colônia de pescadores Z-16 de Cametá e Prefeitura Municipal. 
Nele, foram definidas regras, como proibir pesca de piaba, uso de puçá, lanterna de carbureto, malhadeira no poço, pari, zagaia, flecha do fundo, motosserra, assim como proibir o corte da vegetação da beira do rio, a caça de animais silvestres e práticas que pudessem prejudicar o meio ambiente. O acordo permitia, explicitamente, a utilização de rede aberta para o manejo do pescado, o uso de matapi grosso e pesca com caniço ou linha de mão.

Também foi escolhido um coordenador para administrar e orientar os pescadores no decorrer da existência do acordo durante alguns anos. Nesse período, dois coordenadores do acordo de pesca de Jacaré Xingu (ambos da comunidade), em reuniões e conversa com várias pessoas, conseguiram criar um fundo para a comunidade, constituído de metade do peixe capturado. O objetivo era conseguir recursos para comunidade e fundar uma associação.

Para fundar a associação, os moradores tiveram o apoio do contador e do presidente da Colônia Z-16 de Cametá, que foi criada em 2006 com o nome Associação dos Moradores de Jacaré Xingu (ASMOJAX), que passou a representar juridicamente os moradores. A criação da associação também foi estimulada pelo Instituto Nacional de Colonização e Reforma Agrária (INCRA), uma vez que a ilha passaria a ser concebida e regularizada como Projeto de Assentamento Agroextrativista.

Da mesma forma que no caso de Jaracuera Grande, em Jacaré Xingu ocorreram vários conflitos durante o processo de organização do acordo, pois alguns moradores não concordavam com ele, nem em mudar suas práticas de pesca. Havia o receio, por parte deste grupo, em ficar sem o peixe, dada a visível escassez, o que estimulava as pessoas a intensificar as estratégias de pesca que permitissem obter o pescado para a alimentação da família. Dessa for- ma, esse grupo não respeitava o acordo construído localmente, provocando inúmeros confrontos, discussões, incluindo violência física e ameaça de morte dos coordenadores.

Com o apoio do IBAMA e da Polícia Militar, os líderes da criação do acordo de pesca conseguiram consolidá-lo após meses de palestras e debates para conscientizar a população de que aquele era o melhor caminho para conservar o recurso natural. A presença do Estado nesse momento foi fundamental para a regulação do conflito. Entretanto, passados alguns meses sem a presença do IBAMA e da Polícia Militar, os conflitos voltaram e intensificaram e, assim, a iniciativa do acordo de pesca não teve sucesso.

A partir dos problemas decorrentes da intensificação da pesca, a Colônia de Pescadores Z-16 reuniu os moradores com objetivo de criar um espaço de discussão coletiva, formar pessoas, em parceria com a APACC, sobre práticas agroecológicas de desenvolvimento sustentável, para chegar até a proposição de criação do segundo acordo de pesca de Jacaré Xingu. Esse processo de elaboração foi iniciado em 2005 e concluído em 2007. A formalização do acordo e a versão escrita do mesmo contou com o auxílio de um técnico do IBAMA, visando atender a Instrução Normativa IBAMA $\mathrm{N}^{\circ} 29$ de dezembro de 2002.

Para a legalização do acordo, a proposta aprovada pela comunidade na assembleia foi encaminhada à Gerência Executiva do IBAMA no Estado, pedindo a regulamentação do acordo, por meio de Portaria Normativa Complementar. Juntamente com esse documento, foi encaminhada a Ata da assembleia que aprovou o acordo, com as assinaturas dos participantes.

O acompanhamento da tramitação do 
processo que transforma o acordo negociado localmente em instrumento jurídico legalizado pelo Estado é fundamental, pois em situações de tensões e conflitos, como no caso da comunidade Jacaré Xingu, a não existência do acordo formal pode ter como consequência o descrédito das formas de organização local e o esfacelamento dos acordos negociados, ampliando o conflito socioambiental, em virtude da necessidade premente dos indivíduos de acessar os recursos de uma forma ou de outra.

$\mathrm{O}$ acordo de pesca trouxe muitos benefícios para a comunidade. Por meio dele, os moradores construíram uma associação que hoje administra o projeto de Assentamento Agroextrativista (PAE). Este é fruto de uma parceria técnica entre a Superintendência da União (SPU) e o INCRA, assinada em novembro de 2005, que prevê a transformação das ilhas, consideradas áreas de marinhas e pertencentes à União, em projeto de assentamento sustentável.

O acordo aumentou, significativamente, a qualidade e quantidade do pescado, segundo a percepção dos moradores, com as novas regras, aumentando a produtividade e, principalmente, a renda das famílias. Com ele, muitos peixes que estavam desaparecidos surgiram novamente, como a tainha e o curimatã: "Sem o acordo, não há peixe para alimentar a população; nele há respeito, e conforme a quantidade manejada é distribuída entre todos, mesmo às pessoas de outras comunidades" - afirma um dos pescadores e liderança comunitária.

As principais espécies pescadas são: mapará, tucunaré, dourada, sarda, pescada, tainha, mandubé, caratinga, jatuarana e o camarão-de-água-doce. Entre todas essas espécies, o mapará se destaca como o pescado mais importante, segundo os pescadores.
A maioria dos pescadores dessa comunidade trabalha com o extrativismo do açaí (responsável pela maior parte da renda familiar), criação de pequenos animais (xerimbabos), confecção artesanal de paneiros (feitos de fibras naturais, jacitara principalmente), além de complementarem a renda familiar com aposentadorias, pensões e bolsa família.

Para fazer funcionar o acordo, a comunidade se organiza e faz reuniões mensais. Os pescadores relatam que a ASMOJAX não tem o apoio do IBAMA, nem da Polícia Militar, nem da Prefeitura, que inicialmente incentivavam os acordos, o que dificulta o trabalho de fiscalização. Os entrevistados informam que quando vão ao IBAMA solicitar a presença nas reuniões, os técnicos do órgão não comparecem, alegando falta de recursos financeiros.

Todavia, a associação conta com o apoio da Colônia de Pescadores Z-16 de Cametá e a comunidade local para dar continuidade ao acordo de pesca. O Estado que, de um lado, apoia, estimula, participa na construção da gestão negociada dos recursos naturais, de outro, não cumpre suas funções em um sistema de cogestão, pois transfere todas as suas funções para a sociedade civil e não aceita cumprir, inclusive, as suas funções intrasferíveis por lei, como por exemplo, aplicações de sanções.

$\mathrm{Na}$ reabertura da pesca, quando inicia a pesca do mapará (principal pescaria da região chamada localmente de borqueio derivada de bloqueio), a captura é dividida em $50 \%$ para comunidade e $50 \%$ para o dono da rede (redeiro), que geralmente é de outra comunidade. Dos 50\% da comunidade, 10\% são do "dono da beira" (ribeirinho) que reside em frente à área onde ocorreu a pesca, chamada de poço, conforme consta no acordo de pesca.

Para fazer a divisão do pescado, a comuni- 
dade é dividida em grupos de 20 famílias, cada uma com um coordenador. A partir dessa divisão, cada coordenador recebe o pescado do seu grupo, divide em partes iguais e distribui para cada casa.

Segundo os moradores, o evento mais prejudicial à população ribeirinha de Jacaré Xingu foi a construção da hidrelétrica de Tucuruí (UHT) nos anos 1980. Segundo PDA (2006), os acordos se constituem como o elemento central de novas estratégias de manejo dos recursos pesqueiros, adaptadas às condições ambientais, surgidas após a construção da barragem de Tucuruí.

A comunidade, por estar localizada próximo à jusante do Rio Tocantins, teve a produção de várias espécies de peixes que antes eram abundantes, como o curimatã, aracu, pirapitinga, aruanã, peixinho branco, sarda, tainha e dourada. Outra consequência foi a baixa no nível de água dos rios, resultando no sugimento de praias e pequenas ilhas. Além disso, principalmente no período do verão, aparece um limo verde que desce da barragem, poluindo a água e causando problemas de saúde para população, como diarreia, vômito, coceira, malária e, principalmente, hepatite. Os moradores relatam também que inúmeras famílias deixaram suas propriedades e foram em busca de melhores condições de vida na cidade, muitas vezes, sem condição nenhuma de se manter.

\section{CONCLUSÃO}

Por meio do acordo de pesca, os pescadores afirmam que conseguiram conservar melhor o recurso pesqueiro e garantir a alimentação familiar. No processo de criação dos acordos, a comunidade aprendeu a resolver problemas e apresentar soluções, obtendo um vasto conhecimento, principalmente no que diz respeito às práticas sustentáveis e diferentes iniciativas de manejo. A partir da interação com ações governamentais, também puderam conhecer a legislação e outros procedimentos institucionais que contribuíram para o sucesso das associações. A intervenção de ONGs como a Associação Paraense de Apoio às Comunidades Carentes (APACC) foi muito importante, pois desenvolveu ações fundamentais para a promoção do desenvolvimento rural sustentável, com a realização de cursos, palestras, oficinas e seminários que deram apoio técnico aos camponeses ribeirinhos.

O acordo de pesca abriu um leque de oportunidade aos pescadores, assim como valorizou o conhecimento dos moradores locais e isso contribuiu de forma positiva para a realização e efetivação do acordo de pesca de Jacaré Xingu, por exemplo. Sem dúvida, esse trabalho mostra que a ação coletiva, juntamente com a ação governamental, pode transformar o espaço vivido em um território de ação pública.

Várias inovações são feitas nos acordos apresentados dessa região. A divisão do pescado com a comunidade é uma inovação que não acontece na região do Baixo Amazonas, assim como o pagamento ao residente em frente ao local em que ocorreu a pesca. Entretanto, a divisão da pesca com a comunidade aparenta ser uma forma positiva de envolver a comunidade no acordo de pesca.

No caso de Jaracuera, a divisão do restante da receita do pescado com as pessoas designadas para fazer a fiscalização também é uma forma de compensar os indivíduos na comunidade que dedicam mais tempo para os acordos.

Em relação ao processo de implementação, a maioria dos acordos de pesca em Cametá foi incentivada pelo governo e pela colônia e, talvez por isso, não obteve sucesso (De 
Castro et al. submetido). Grande parte dos acordos não foi legalizada e vários acordos foram escritos, mas não foram implementados. Ao mesmo tempo, enquanto no Baixo Amazonas as ONGs externas às comunidades foram fundamentais para $\mathrm{O}$ sucesso, como Projeto Iara e IPAM, com trabalhos de longo prazo para fortalecer a organização dos pescadores, esses dois processos analisados foram genuinamente organizados pelos moradores das comunidades.

Conforme afirma De Castro et al. (submetido), as agências do estado tem substituído o processo de baixo para cima por processos rápidos, liderados por representantes do governo, que comprometem a legitimidade e geram documentos que não refletem processos e iniciativas de interesse das comunidades. Isso seria uma razão para que quase todos os 40 acordos estudados por De Castro et al. (submetido) não tenham tido sucesso.

As duas experiências aqui descritas, entretanto, são distintas da grande maioria das experiências de acordo de pesca de Cametá, já que foram originadas nas comunidades e organizadas por elas, mostrando que, a não ser que o processos sejam oriundos de dentro das comunidades, a legislação e instrução normativa, por si só, contribuem pouco para implementação e sucesso de acordos de pesca efeitos (De Castro et al. submetido).

\section{NOTAS}

${ }^{1}$ Comunidade do Perpétuo Socorro e São José, a Igreja Adventista da Promessa, a igreja Assembleia de Deus, o Escritório Regional de Cametá do IBAMA, a Colônia de pescadores Z-16, a Secretaria Municipal de Agricultura, a Delegacia de Polícia e o Sindicato dos Trabalhadores Rurais pertencentes a Cametá.
${ }^{2}$ Com base nas atas.

\section{AGRADECIMENTOS}

Este trabalho se beneficiou do apoio da Agência Nacional de Pesquisa (França), no marco do programa SYSTERRA, ANR09-STRA-04, e do PROEXT - MEC/ SESu - programa Baixo Tocantins (PROGBAT) - desenvolvido pelo Grupo de Estudos sobre a Diversidade da Agricultura Familiar (GEDAF). Também foi beneficiado com apoio do IDRC, FAPESPA,CAPES e CNPQ

\section{REFERÊNCIAS}

Almeida, O. et al. 2009. Fishing agreements in the Lower Amazon: for gain and restraint. Fisheries Management and Ecology 16 (1):61-67.

Barthem, R.B. 1995. Development of commercial fisheries in the Amazon basin and consqueces for fish stocks and subsistence fishing, in Brasilian prespective on sustainavle development of the Amazon region. Editado por M. Clusener-Godt, \& I. Sachs, pp. 175-204 Paris: Unesco e Parthenon Publishing.

Carvalho, H. M. 1998. Formas de associativismo vivenciadas pelos trabalhadores rurais nas áreas oficiais de reforma agrária no Brasil. Curitiba: IICA/MEPF/NEAD. Disponível em http://www.dataterra.org.br. Acesso em: 23 jul. 2012.

D’Incao, M. C., \& G. Roy. 1995. Nós cidadãos: Aprendendo e ensinado a democracia. São Paulo: Editora Paz e Terra.

De Castro F. 1999. Fishing Accords: the political ecology of fishing intensification in the Amazon. Tese de Doutorado, Universidade de Indiana, EUA.

De Castro, F. et al. (submetido) Forma- 
lization of local fishing management systems in the amazonian estuary. Human Organization.

Dubet, F. 1987. La galère: jeunes en survie. Paris: Editions Fayard.

Dubet, F., \& M. Wieworka. (Eds.). 1995. Penser le sujet. Paris: Editions Fayard.

Duran, P. 1999. Penser l'action publique. Paris: LGDJ.

Fernandez-Baca, J. 1998. Amazonian Fisheries: socio economic issues and management implications. London: Discussion Paper 98-02.

Gohn, M.G. 1997. Teoria dos movimentos sociais: paradigmas clássicos e contemporâneos. São Paulo: Edições Loyola.

Lascoumes, P., \& P. Le Galès. 2007. Sociologie de l'action publique. Paris: Armand Colin. Leloup, F. et al. 2005. La gouvernance territoriale comme noveau mode de coordination territorial? Géographie, Économie, Société 7(4):321-332.

McGrath, D. G. et al. 1993. Fisheries and evolution of resource management on the Baixo Amazonas floodplain. Human Ecology 21:167-195.

Melucci, A. 2001. Vivencia y convivencia. Teoría social para una era de la información. Madrid: Editorial Trotta. 181 p.

Olson, M. 1965. The logic of collective action. Cambridge: Harvard University Press.

Oliveira, A. \& L. Cunha. 2000. Community management of the floodplain lakes of the middle Solimões River, Amazonas State, Brazil: a model of preservation in transformation, in Proceedings of the 8th Biennial Conference of the International Association for the Study of Common Property (IASCP). Disponível em http://129.79.82.27/ IASCP00/program.asp. e cd.

Pereira, H. 2000. The emergence of common-property regimes in amazonian fi- sheries, in Proceedings of the 8th Biennial Conference of the International Association for the Study of Common Property (IASCP). Disponível em http://129.79.82.27/IASCP00/ program.asp. e cd.

Queiroz H. 1999. A pesca, as pescarias e os pescadores de Mamirauá, in Estratégias para manejo de recursos pesqueiros em Mamiraná. Editado por H. Queiroz, \& W. Crampton, pp. 37-71. Brasília: Sociedade Civl Mamiraua/CNPq.

Simões, A. 2007. La réforme agraire en Amazonie brésilienne: innovation et apprentissage social. Tese de Doutorado, Instituto de Pesquisa para o Desenvolvimento, Universidade de Toulouse le Mirail, França.

Smith, R. 2000. Community-based resource control and management in the Amazonia: A research initiative to identify conditioning factor for positive outcomes, in Proceedings of the 8th Biennial Conference of the International Association for the Study of Common Property (IASCP). 20 pp. Disponível em http://129.79.82.27/IASCP00/ program.asp. e cd.

Touraine, A. 2006. Un nuevo paradigma para comprender el mundo de boy. Buenos Aires: Paidós.

Vidal, M. D. 2010. Manejo participativo da pesca na Amazônia: A experiência do Pró-Várzea. Ciência e Natura 32: 97-120.

Recebido em 27/08/2013

Aprovado em 21/11/2013 